\title{
STONE CLUBS OF NEW GUINEA
}

\author{
Martin Soukup ${ }^{1}$
}

\begin{abstract}
The topic of this study is a description and analysis of stone clubs made in New Guinea during pre-colonial era and following first decades of colonialism. The study describes a typology of stone clubs and talks about the areas of their origin. Paper reveals eight types of clubs, differentiating these further according to (five) areas in New Guinea where these were fabricated. The cultural context of club usage is also provided.
\end{abstract}

KEYWORDS: stone club - stone manufacturing - New Guinea - warfare - head-hunting

\section{Introduction}

The rich language diversification has emerged in New Guinea, the largest tropical island in the world. Estimate figures show there are more than eight hundred of local languages, whereas some of them are language isolates. There is also a vast diversity of material culture with many regional styles. Speaking of those, some artifacts, like string bags $^{2}$ or drums with a typical sand-glass shaped pattern, ${ }^{3}$ were widespread within the whole island. Notable is the use of stone for the tool making, since iron was not used in this area before colonial era. Thus, stone manufacturing was crucial in everyday-life tool as well as warfare production: axes, mortars, beaters, stone clubs, and spear throwers [Fig. 1]. Stone was also used for crafting religious items and valuables. Technology of a metal processing remained unknown for the most of New Guinea, with exception of the north-west territory, where some bronze artifacts were documented. Such exception naturally arose from trading contacts with certain Sinophone districts, ${ }^{4}$ where a melting technique was already practiced.

One of the aforementioned 'widespread artifacts' in New Guinea were warfare stone clubs. These were very efficient and dangerous weapons, as first upcoming Europeans and Australians had a chance to find out while exploring the inland Highlands. Well known gold miner Mick Leahy was attacked by warriors from Anga group when camping north-west from Watut river. Leahy was hit by pineapple type stone club to his head, after which his hearing on the right side was disabled and he suffered from tinnitus for the rest of his life. ${ }^{5} \mathrm{~A}$ few days earlier, the same group attacked another gold miners'

1 Contact: Martin Soukup, Palacký University Olomouc - Faculty of Arts, Olomouc, Czech Republic; e-mail: martin.soukup@upol.cz; This study was supported from European Regional Development Fund - Project Sinophone Borderlands - Interaction at the Edges CZ.02.1.01/0.0/0.0/16_019/0000791.

2 MacKenzie 1991.

3 Fischer 1986.

$4 \quad$ Swadling 1996.

5 Connolly and Anderson 1988.

This work is licensed under the Creative Commons Attribution-Noncommercial-No Devivs 3.0 License 


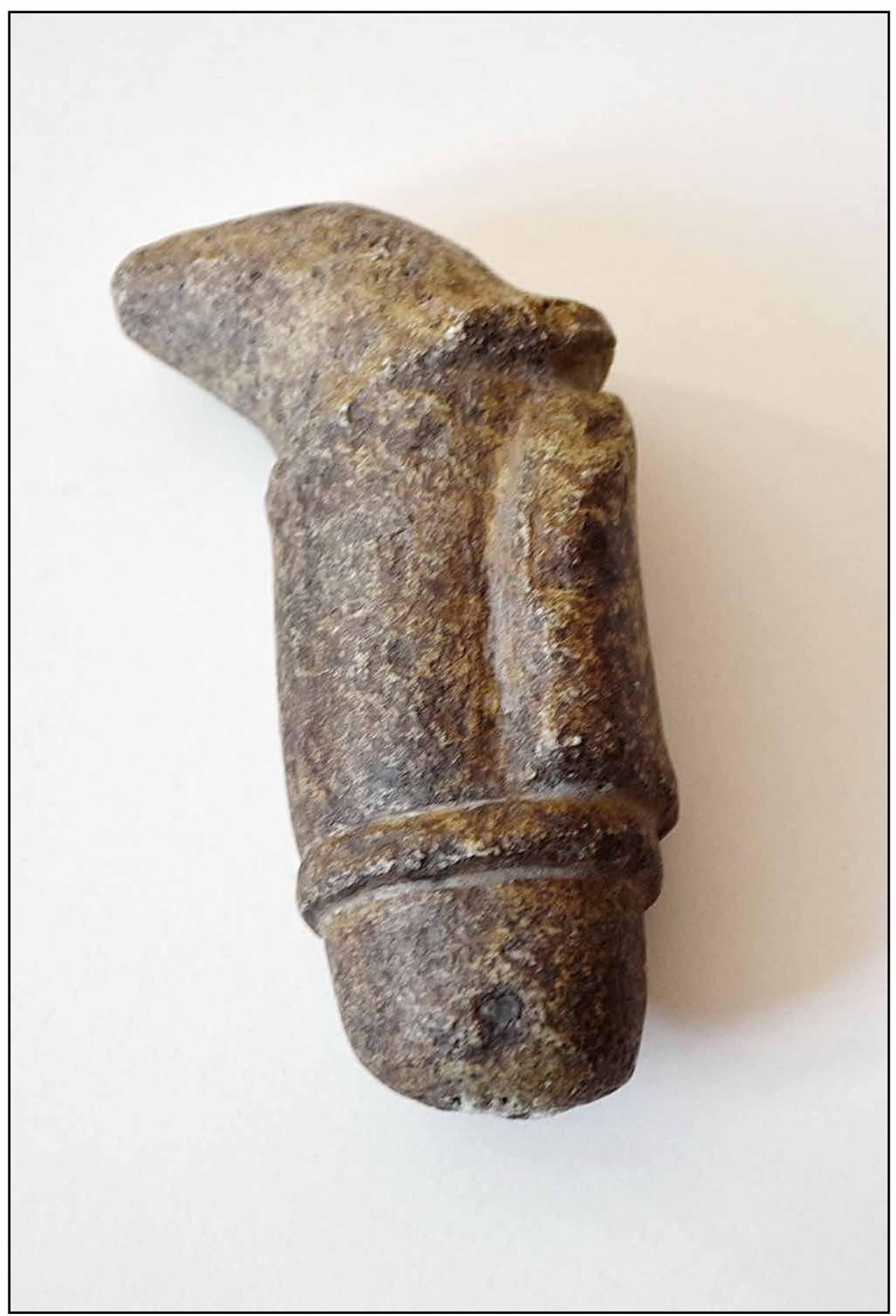

Fig. 1. An example of stone pestle from New Guinea Highlands. A private collection (Photo: Martin Soukup). 
encampment, killing Helmuth Baum with stone club. ${ }^{6}$ Similar incidents provide evidence that stone clubs were produced and used in 1930s. After the World War II, elders declared that stone clubs were already not being made for one generation at least. The main goal of this study however aims mainly to introduce the types and distribution of stone clubs in New Guinea. The author of the first classification in this field is Alfred Haddon, ${ }^{7}$ who published a typology of heads of stone clubs in his study, where he provided an evolutionary scheme of clubs, let's say 'phylogeny' of the particular types, which was corresponding to his diachronic approach to the study of culture, articulated in publication Evolution of Arts $(1895)^{8}$ and others. From today's point of view, this evolution-typology classification was limited, however that was neither due to its thesis being based on diffusionism (diachronic approach) and the lack of diversity documentation, nor because Haddon didn't have access to the Highlands and its cultural variability. Rather, it was his data talking about geographical and cultural origin of items within his collection not being complex, limiting his understanding of the evolution pattern of stone clubs' development and their spatial distribution. The study is based on literature search and examination of stone clubs held in three Czech private collection.

\section{Stone and stone clubs manufacture}

Human presence was documented fifty thousand years ago in New Guinea, but it's not excepted people were living there even earlier. One of the oldest evidence of their presence are findings including stone tools, which were discovered in Highlands. ${ }^{9}$ Local people shaped stones by dipping them into a water while rubbing them over other stones until sharp. When it should become dull again, the stone could have been repeatedly sharpened or re-shaped. ${ }^{10}$ As new stone wasn't always accessible for communities, there was a demand to get a new material through exchange. For example, Dugum Dani group, who was researched by Karl Heider, gained new stones suitable for axes crafting from areas located 150 kilometers away. ${ }^{11}$ Paul Sillitoe ${ }^{12}$ have found out that the Wola imported axe blades from Western Highlands. In Torres Strait, locals got their stones by picking them from a bottom of the sea or by trading new stones for goods with inland communities of New Guinea ${ }^{13}$ who had better access to desired raw material. Exchange trade was common even between distant areas and it could easily extend over hundreds of kilometers, as the spread of ceremonial axes from Mt. Hagen shows; all material used for these particular axes' making originated in one area, from which the axes traveled all around Highlands. ${ }^{14}$ This complex exchange trade network existed for thousands of years in New Guinea. ${ }^{15}$ Chappell and Strathern ${ }^{16}$ stud-

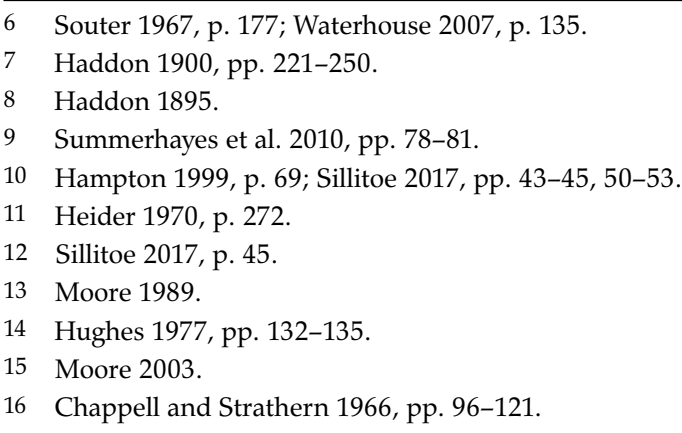


ied in detail both quarry sites and the sites where the stone axe had been made in East New Guinea. They showed the complexity of exchange network in New Guinea Highlands.

Stone clubs were manufactured in various shapes and areas. Beatrice Blackwood was observing the stone clubs manufacturing during her field research of Anga group (known as Kukukuku before) in 1920s. Her work is unique because she had a chance to observe perhaps very last stone club crafters. Ball-shaped clubs were distinct for them, but the other types - disc and pineapple - were crafted by nearby groups. In the time of her research, the Australian administration did not control Highlands, so the permission for her fieldwork was not easy to get. Anga group was one of those who remained aside of administration control for a long time. That is why her research findings are so unique and valued today.

The Anga group is often mentioned in connection with cannibalism and use of stone clubs during warfare (see below). Blackwood documented specific manufacturing method of head of stone club, for which the stones picked in rivers were used. The suitable bigger stones could have been found in lower river areas of Kiapou, Langimar, or Watut, as their tributaries in their upper parts usually did not provide stones of proper size and quality. Blackwood did not observe that Anga people would perform a massive shaping of the stones; they simply chose round shaped one and just drilled a hole for a handle. An ideal placement for the hole was selected by balancing a stone in one's fingers, then the mark was made on the opposite sides to determine proper place for hole. Drilling was performed from both sides, resembling the tunnel making. The finished head could be finalized by chipping the stone away or rather by rubbing it over other stone. The handle was then housed to the head: old tapa was wrapped around the designated end, handle was inserted into the hole in the stone for a correct positioning of rattan securing pin, then the head was removed. Right under the tapa, the rattan strings were tightened with bone awl, forming crisscross pattern. Stone was fitted back on to tighten the rattan patterns, it was then removed again, and taken in the fire pit to 'make it good'. Meanwhile, the upper part of the rattan pattern was sewn. The club was finally completed, the stone was secured with the both rattan patterns being lastly tightened, and the excess tapa was cut off. To secure the stone head, a wedge was hammered into the haft, firming up the whole weapon. The very last step was the club balancing, which was done with following procedure: club was rotated over a head of its user yielding the proper length. Excess handle was cut. ${ }^{17}$ This had a very practical result; even nowadays, when you hold the weapon, you can feel it fits naturally, due to the described balancing.

\section{Typology of stone clubs}

First attempt on this field, as stated earlier in this text, was done by Alfred Cort Haddon. ${ }^{18}$ Despite commented (and limited) overlap of his text into present times, his vision of heads of stone club development can be used as introduction into this issue, well illustrating, among the issue itself, the lack of information he faced. In Haddon's view, everything started with a raw stone, originally used without modifications, when only eventually it was possible to start to produce more complex shapes like coils, spheres,

17 Blackwood 1978, pp. 95-96.

18 Haddon 1900, pp. 221-250. 
eggs, and pineapples (which Haddon specified with the term 'knobbed'). According to his classification; if the stone was oval shaped, it enabled move towards disc-shaped stones, discs with notches, pickaxes, and stars. Haddon differentiated 'the pickaxe' and 'the star', standing both for different groups. His key in differentiation between these two was based upon a claim that there were two tips on the pickaxe, but in fact, there were two bigger peaks on one axis, whereas perpendicularly, there were other two smaller peaks, forming together a four-tip star. Thus, current classification considers the pickaxe as a sub-type of star. Haddon's scheme tried to establish an order, where such is not necessary; the final appearance of the head of stone club was defined by the shape of the raw stone before crafting anyways. Manufacturing, that consisted of grinding and rubbing was indeed laborious, for that it is not a surprise that people were trying to avoid it as unnecessary. It typically had taken about ten hours to completely produce a finally shaped stone for a stone axe; to finalize a stone axe had taken nearly sixty hours [Fig. 2]. ${ }^{19}$

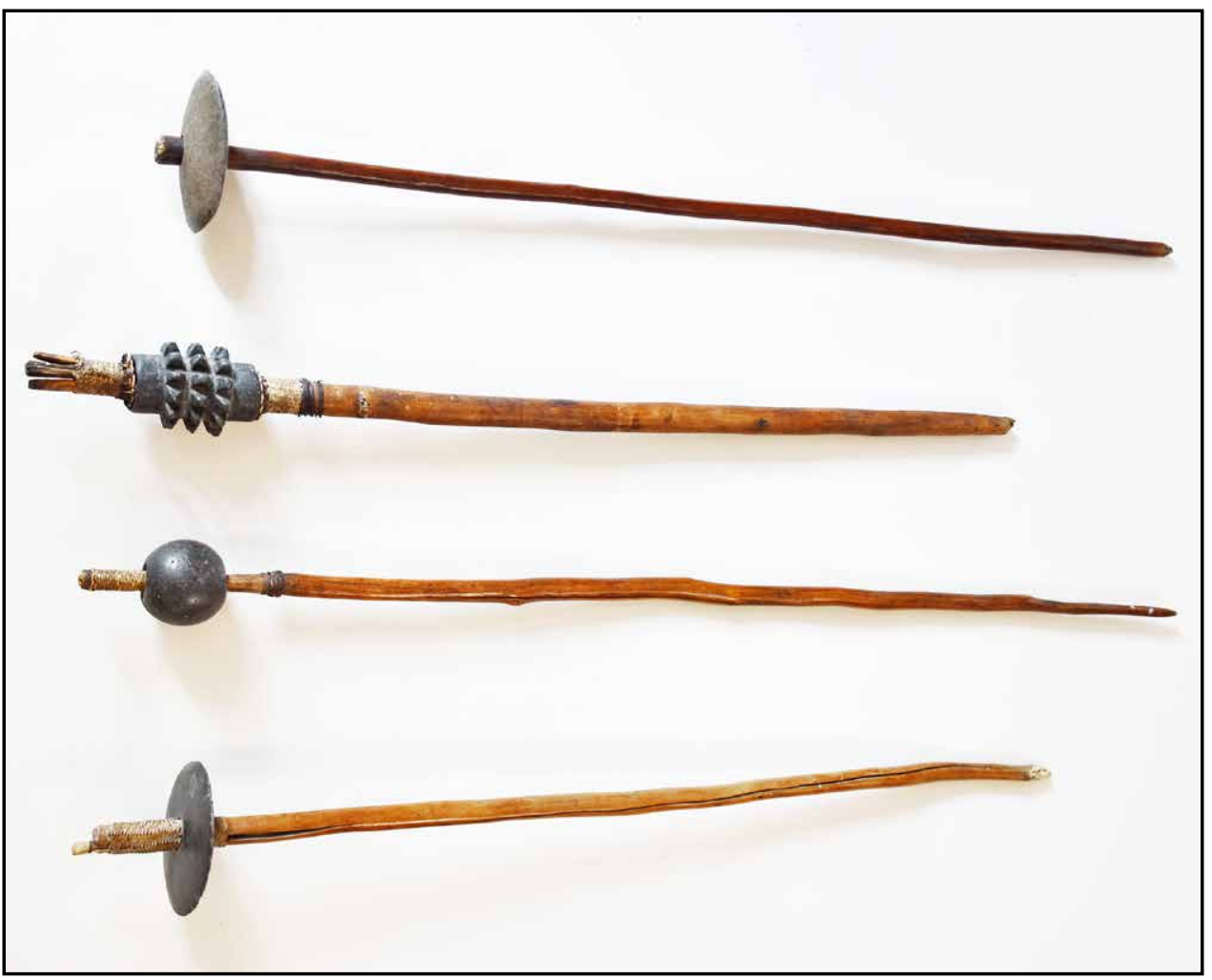

Fig. 2. Stone clubs: ovoid type, pineapple type, ball type, disc type (from top to bottom). A private collection (Photo: Martin Soukup). 
Today, we recognize eight types of warfare clubs, differentiated according to the shape of their heads: ball, knobbed ball, ring, oval, pineapple, disc, cog, star, and starfish. The main problem of this classification is somewhat limited possibility of geographical linking of these with their origin. The stone clubs from Kamoro area are example of exception from this rule. Kamoro people did not have access to raw stones as basalt and slate stone, their environment offered them sandstone only. Kamoro sandstone heads were shaped into balls, knobbed balls, stars, or cog shapes, and due to the material used, the heads were never smooth. Marind-Anim people were making disc shaped stone clubs only, as well as Asmats, who were producing solely disc and star shapes (see below). These examples, however, should count as an exception in determination of the origin of the stone club heads correctly, as in general, all types of stone clubs were crafted practically in every known locality. Opinions connecting particular types of clubs with the regions of their sole occurrence arose, but these were never generally affirmed. Such an idea may be illustrated with example of pineapple stone clubs, being preferred around Kutubu lake. Ovoid and sphere shapes were popular in Upper Watut (Anga group) and finally, discshaped clubs with radial knobs were produced by the river Kapau. ${ }^{20}$ Yet, it should be noted that specific style of the stone clubs and its dedication to the particular culture group or area remains an exception from general rule that all the shapes of clubs were crafted everywhere. The essential problem is that artifacts collected in the past lack provenance data, which unfortunately make it difficult to study them further. A lot of museum and private collections do not have a provenance, but if the collector and his/her itinerary is known there is a solid chance to determine the origins of particular specimens and make a link between type and a particular cultural group.

Similar uncertainty - as there is with origin of the heads of the stone club - surrounds the handles with their attachment to the head; neither here we seem to be finding a way to localize the club according to this design. There are three basic types of attachments of stone to the haft: (1) without fixation' instruments; (2) using wedge and crisscross pattern; (3) crisscross pattern only.

1. The first of aforementioned designs utilized a specifically shaped handle, where the stone was secured to the haft, as the haft widened along its' length, ending with a wide tip. Such system disallowed falling of the stone during a hit. This fashion of club making is known from Asmat, Marind-Asmat, and also from Eastern and Southern Highlands [Fig. 3].

2. The combined fixation design used wedge and rattan crisscross pattern, which held the stone in place with the different principle. The stone was set on the haft, moved to one end of it and then the wedge was hammered into the haft forming a split. In the end, the rattan patterns were added to secure the stone and to tighten the haft up also. Those stone clubs were found in various areas in Eastern Highlands or Papuan Gulf [Fig. 4]. 


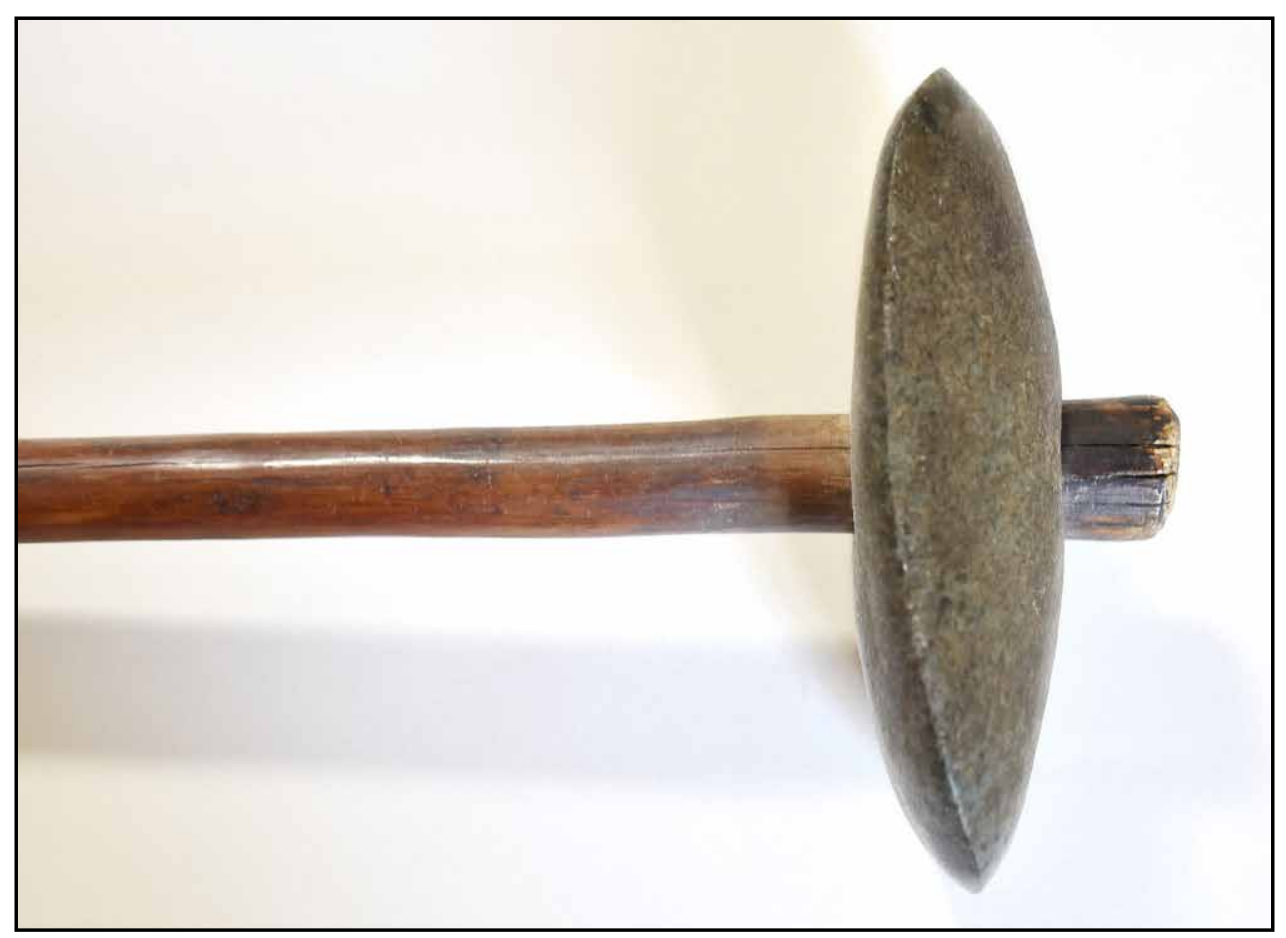

Fig. 3. Attachment of the head to the haft without fixation' instruments. A private collection (Photo: Martin Soukup).

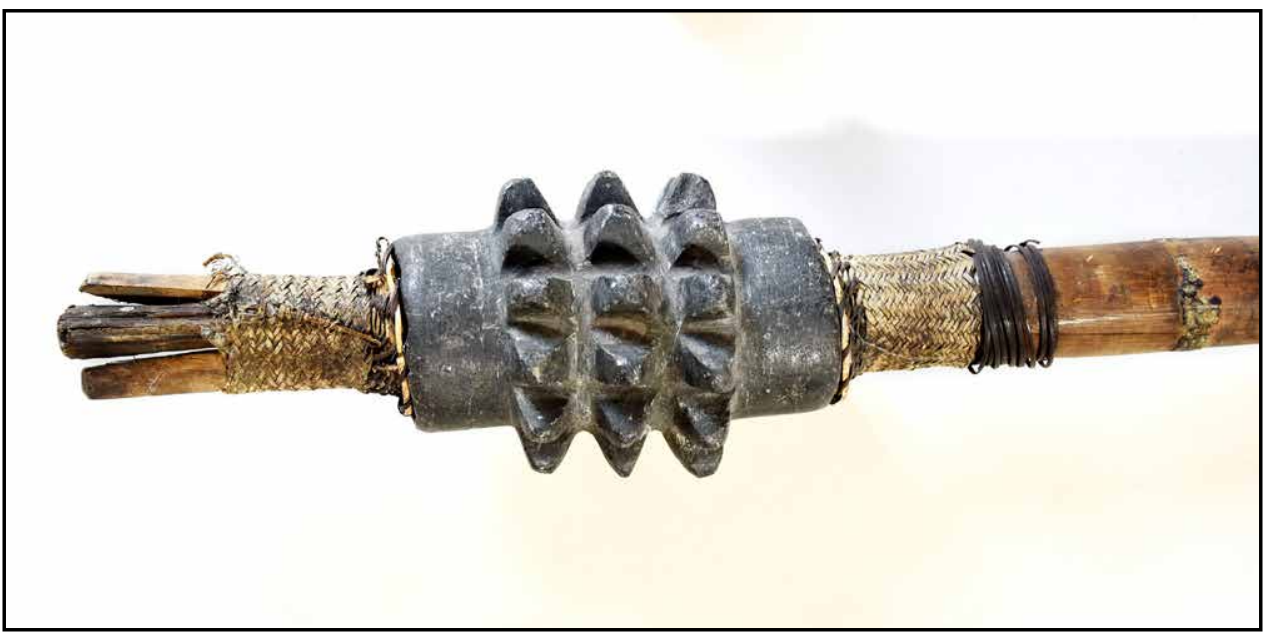

Fig. 4. Attachment of the head to the haft using wedge and crisscross pattern. A private collection (Photo: Martin Soukup). 


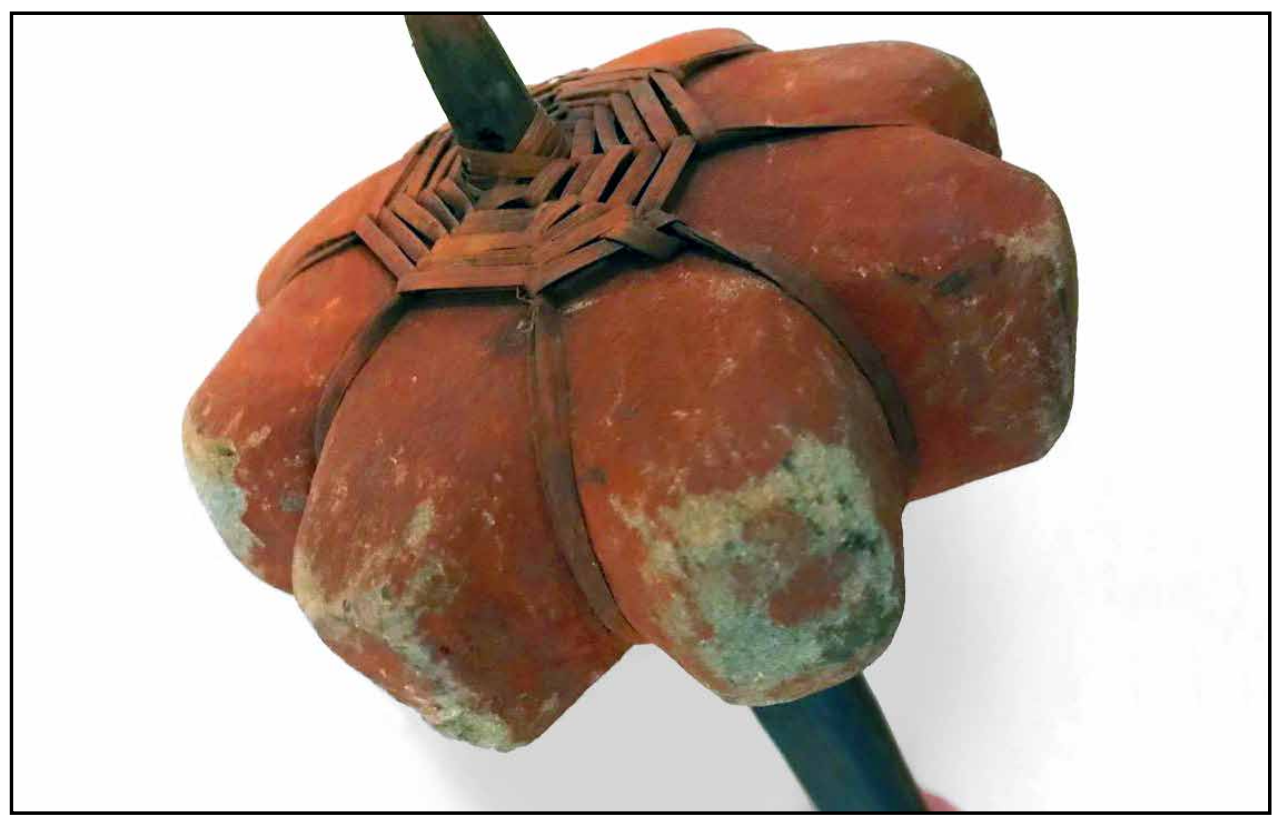

Fig. 5. Attachment of the head to the haft using crisscross pattern only. A private collection (Photo: Dušan Lužný).

3. The last type of stone fixation is the least common: the stone was held with just crisscross rattan pattern above and beneath the head, with additional rope tied around the body of the stone. Those stone clubs are typical for Kamoro group, but some pieces were produced in Eastern Highlands area as well [Fig. 5].

\section{Spreading of the stone clubs}

Warfare stone clubs were not manufactured in New Guinea only, region of their production included various areas of Melanesia; they were, for example, used by Tolai people in New Britain. This was not only group of New Britain using stone clubs; Parkinson $^{21}$ extensively refers about Baining peoples' usage of this weapon, he also provided a detailed description of the manufacturing of stone heads by the Baining people. As archeological findings prove, the stone club usage was widespread before oral history times in Highlands; a testimony of oral history usually covers no more than four generations. Roughly, from the perspective of Westerners, a native oral history was barely referring more than mid of $19^{\text {th }}$ century if we take in an account that a more intensive contact with New Guinea natives have started in the end of $19^{\text {th }}$ century. The natives typically refer to the past using pidgin English words 'taim bipo' (in a past) or 'em bilong tumbuna taim' (in the time of ancestors). There are many unintentional archeological findings in native gardens; including stone clubs which the natives are usually trying to interpret somehow. Pretty ${ }^{22}$ referred about two findings of heads of the stone clubs

21 Parkinson 2010, pp. 73-74.

22 Pretty 1964, p. 117. 
- disc and sphere shaped - found in Nundugul field-site (Western Highlands); findings like this aren't unique in Central Highlands. Local elders, however, expressed an opinion, that the mentioned stone clubs were, 'things from the past and we can just guess what they were for'. Stone clubs were typical for some provinces of Eastern and Southern Highlands, but they weren't everywhere (in addition, the borderlines of cultural areas didn't follow the borderlines established by colonial government, bringing another localization challenge). For example, stone clubs were crafted and used in the area of lake Kutubu as is evidenced by Williams. ${ }^{23}$ He documented 'inferior specimens' of pineapple type stone clubs. It was evident that stone clubs were no longer made by people living around the lake Kutubu. On the contrary, cultural group Wola, living also in South Highlands, have never used them in 'historic times' ${ }^{24}$ Some of the heads of the stone clubs, coming probably from pre-colonial era, were found by local people during cropping and those became the ritual items. ${ }^{25}$ Not only this example shows that the stone clubs were crafted probably more frequently during pre-colonial times then in historical times in the area of Central Highlands, which could be due to grasslands spreading, occurring some five thousand years ago. Enemies could have been seen from larger distance when forests have disappeared, so circumstances for ambush have changed and the stone clubs weren't suitable for successful attack strategy anymore. Of course, there had been an opportunity to organize an ambush from a shelter of kunai grass which was a typical environment of Highlands.

Main areas of stone club cultures can be specified within New Guinea in a following manner: (1) Southern and Eastern Highlands - Papua New Guinea; (2) Kamoro - Indonesia; (3) Asmat - Indonesia; (4) Marind-Anim and Suki - Indonesia and Papua New Guinea; (5) Papuan Gulf - Papua New Guinea. In the past times, the stone clubs weren't manufactured throughout the whole island, rather it occurred inlands only and these were used solely for warfare, never for hunting. The key purpose of their usage was to hit an enemy over his head from a short distance, eventually to put to death a person who was injured already. Notably, it was never used as throwing weapon. ${ }^{26}$ Also, there are some areas in Central Highlands, where the stone clubs weren't used at all in ancient times probably. Instead, the bows and arrows were fought with, as represented by Kapauku ${ }^{27}$ from Kamu Valley or Dani ${ }^{28}$ from Baliem Valley. The stone manufacturing was well known in these groups, but stone was used for different purposes: every-day life object making, axes for instance, were used for cutting tree and wood chopping. The absence of the stone clubs in this area is not surprising because of local surroundings: clubs are effective only in short-distance fight or during unexpected ambush. It is rather understandable, that bows and arrows were preferred in deforested valleys of Central Highlands.

1. The stone clubs of ball, disc, star, starfish, ovoid, and pineapple shapes, were used in Eastern and Southern Highlands. The greatest popularity of stone club usage within this cultural area enjoyed the Anga group, although these were

23 Williams 1941, p. 145.

24 Sillitoe 2017.

25 Paul Sillitoe, personal communication.

26 Blackwood 1978.

27 Pospisil 1963.

28 Heider 1970. 
also generally used by Tairora or Adzera groups. Jean-Pierre Dutilleux might have captured one of the last 'first contacts' in his movie The Toulambi: First Contact in New Guinea (1976), where men were armed not only with bows and arrows, but there was a chance to see a stone clubs as well. However, those people weren't the members of previously non-contacted group; they were coming from self-isolated Toulabi group (part of Anga people). In another words, the movie itself induced a lot of uncertainties. There should be no doubts that the presented group had occasional external contact with administration, the steel was known to them and they knew some basics of tok pisin the pidgin English. ${ }^{29}$ The Anga group was known for their lack of obligingness to cooperate and to conform to colonial administration and as well for their aggressive attitude towards gold miners. Blackwood said, their enemies ended up being split into quarters, cooked, and eaten. ${ }^{30}$

2. The Kamoro area is located on south-west coast of New Guinea. Their material culture is visually similar to nearby living Asmats and Kamoro artifacts are desired by collectors the same way the Asmats' material culture is. ${ }^{31}$ Visual similarity does not overlap to cultural similarity though. In the contrast to Asmat people, a head-hunting and cannibalism was not a part of the Kamoros' cultural tradition; their mythology and rites also differ from Asmat dramatically. Kamoro people were crafting warfare clubs made of stone and wood, and the stone clubs were ball-, disc-, or star-shaped, for which a soft sandstone and a limestone was used. It is not clear how these stones (perhaps already acquired through trade) ended up in their possession, because there is no stone source in Kamoro area, which is an alluvial plain. The water level is rising and diminishing periodically during the day, which brings along mud and clay. Sandstone, readily available in the area, has not enabled desired sharpening and therefore, was not suitable for stone club manufacturing. Yet, basalt and slate were known to them as being usable for given purpose and for such a reason obtained. The stone was attached to the handle with a wedge or with a rattan fastening, which also crossed the body of the stone. ${ }^{32}$ The same practice was used on Eastern part of the island [Fig. 6].

3. The stone clubs were manufactured in some parts of Asmat region, but certainly not everywhere, due to the reason that stone was not used for crafting things in Central and North-west area of Asmat. The stone clubs manufacturing dominated in the Asmat area of $\mathrm{Citak}^{33}$ where clubs, employing the discs or stars, were done by attaching them to the handle without using a wedge or crisscross rattan pattern, securing the stone in place by rattan-around-stone design only. The head-hunting related to cannibalism was performed by Asmat, being the part of rites of passage, in which boys were introduced into an adulthood. Despite the fact that Asmat used bows and arrows more often than clubs for

\footnotetext{
Cf. Lemonnier 2004, pp. 79-98.

Blackwood 1978, pp. 119-121.

Schmidt 2003.

Compare to Kooijman 1984, p. 125.

See the map made by Schmidt 1993, pp. 16-17.
} 


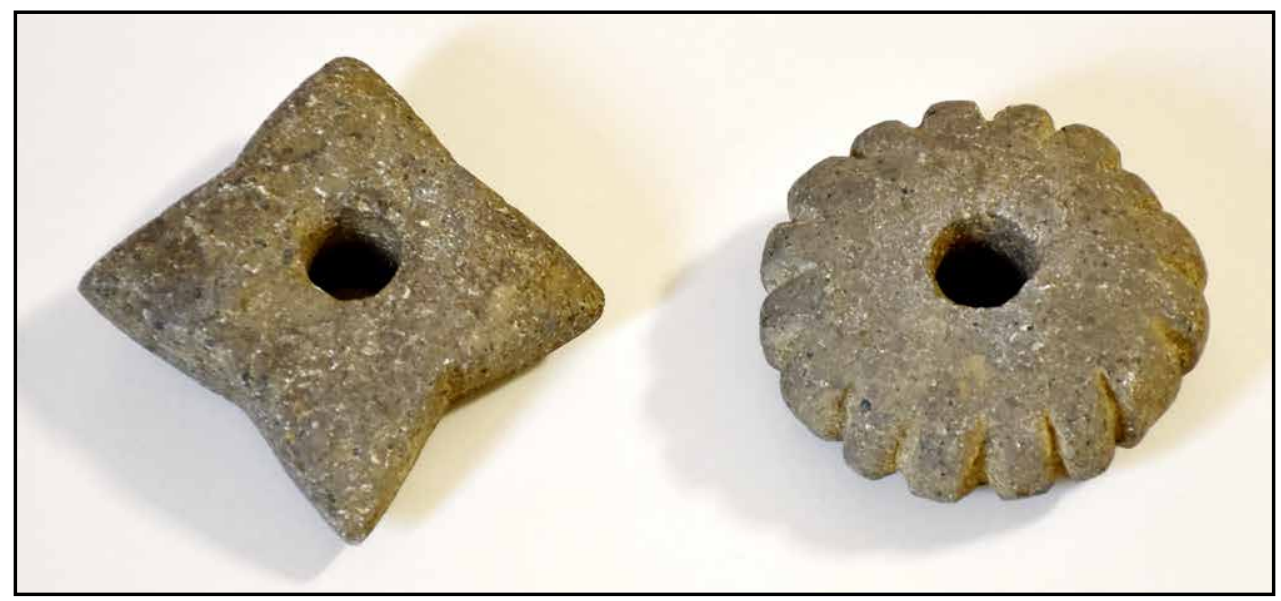

Fig. 6. Heads of stone clubs from Kamoro: a) star-shaped, b) cog-type. A private collection (Photo: Martin Soukup).

warfare purposes, the stone clubs were used too, for skull piercing in particular. Killed people or captives were loaded on a canoe after a successful raid into enemy village and they were taken to the winner's place, where cutting of the body and head preparation happened. The hole was pierced into the parietal bone, though which the brain was taken out, then the stone club or axe got the name of the person being killed with it. ${ }^{34}$ There were no stone clubs north-eastwards of Asmat, despite Kombai and Korowai had a stone crafting skills. They did not use the precious material to produce the stone clubs [Fig. 7].

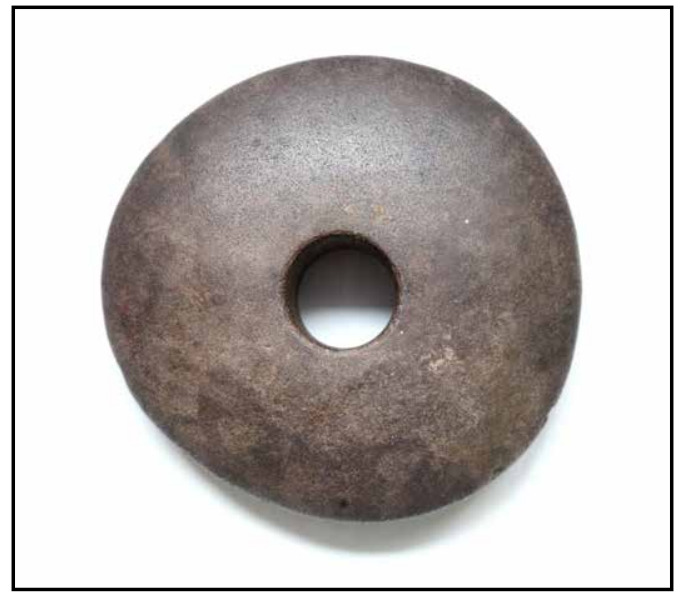

Fig. 7. Head of stone club from Asmat region. A private collection (Photo: Jan Rendek). 
4. In Marind-Anim area, (overlapping to the Fly area, according to current Papua-New Guinea geopolitical structuring) another type of head-hunting in relation with warfare clubs occurred, although it had the connection with the rite of passage as well. Before the victim was killed, he/she was hit with ritual parasi first, equipped with the star or disc-shaped stone, wooden hafting, and with its' upper part richly decorated. Sometimes, the heads of the clubs became imitations being made of a wood, because the stone was after all a precious material and there was a need to import it. The proceeding of this rite was to strike a victim, during which parasi club was smashed. Remains of the decorated part were left with a killed person and warrior took home just the handle and the stone, which slid down the handle after the impact. ${ }^{35}$ Ritual clubs are also described by Williams, who worked as a government anthropologist in Territory of Papua (south-east part of island controlled by Australia until 1975). He declared that the parasi clubs were used by Wiram group (also called Suki), living in inland by the river Fly. According to Williams, those warriors took the same parts from broken parasi with them after the hit, displaying these in the village. Returning without this proof of success condemned the rite to be a failure, bringing a shame to the rite performer. ${ }^{36}$ In either case, the final hit - following the ritual one - was performed with a regular stone club, the same way as among Asmat, who manufactured disc-shaped heads like Marind-Anim did [Fig. 8].

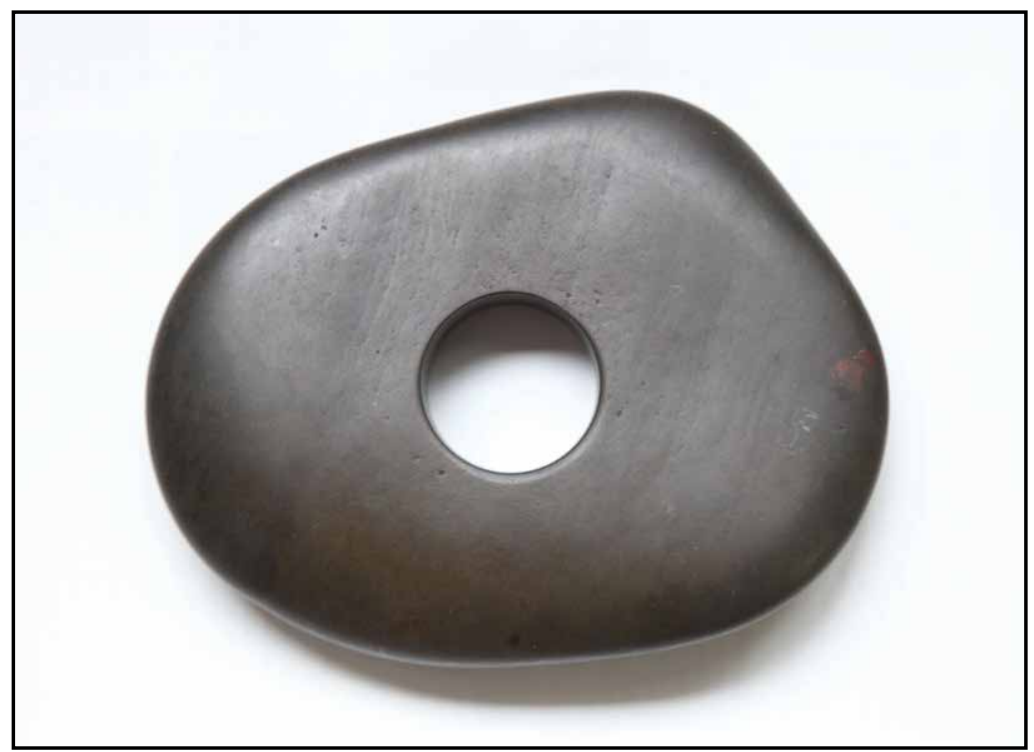

Fig. 8. Head of stone club from Marind-anim region. A private collection (Photo: Jan Rendek). 
5. The stone clubs were used intensively in the area of Papuan Gulf, their production was performed along the whole shore and inland, up to Central Province. Williams described the use of the stone clubs in the end of 1920s in Abau District, photographically documenting the procedure of their crafting. ${ }^{37}$ The stone clubs were used throughout the area of Papuan Gulf, their production has also spread into Kokoda area. It means the production of stone clubs covered Oro Province, there is also the evidence of manufacturing stone clubs in Central Province. The American anthropologist Lewis gained the material for the Chicago's Field Museum of Natural History during his four year stay in Pacific. His collection of stone clubs originates in Mambare river, Kumusi river, Dobudura village, next to Buna Beach, and from Kokoda, comprising of pineapple, ball, and disc-shaped types, with stones secured with rattan crisscross pattern. ${ }^{38}$ The same style of the stone-handle attachment was crafted in specific parts of Papuan Gulf by the Kikori river and Fly river estuaries' cultural areas. Disc shaped head was the most frequent design, although knobbed specimens made from granitic rock were present there, too. The fact, that the haft was crafted from hardwood or bamboo and that it was decorated with ornaments is interesting, because of a huge portion of effort needed to perform such task. The stone for manufacturing was obtained in hinterland of New Guinea ${ }^{39}$, but renown expert of Papuan Gulf, Gunnar Landtman, stated that the stones for clubs manufacturing were gained from the bottom of the sea as well. ${ }^{40}$ Along with already mentioned, the stone clubs in this area also played significant role in cannibalism and head-hunting. One of the most profound incidents was the death of Reverend James Chalmers and his mission helpers. They were killed with the stone club after being hit over the head by Goaribari people. ${ }^{41}$ Chalmers has disappeared with his companion from Kiwai island. Reportedly, they were eaten the same day they were killed. Kiwai people also practiced head-hunting and cannibalism. Victims were killed with the stone club, then with bamboo knife, their head was decapitated and with specific head-carriers, the gained heads were transported back to Kiwai village. It is worth to note that Gunnar Landtman got a very clear evidence of cultural flexibility of islanders in contact with the other cultures. Landtman obtained clubs, in which a stone was replaced by a steel, gathered from shipwrecks. ${ }^{42}$

\section{Conclusion}

The stone club have become an important weapon for numerous communities in New Guinea. Doubtlessly, they were used more frequently during pre-colonial period, according to archeological findings. The main advantage of the stone clubs was linked to the natural battlefield surroundings, because it is the weapon suitable the best for short distance fighting, being therefore preferred in circumstances where the

37 Young and Clark 2001, pp. 155, 158.

38 Lewis and Welsch 1998, p. 509.

39 Moore 1989, pp. 50-51.

40 Landtman 1933, p. 45.

41 See Maiden 2003.

42 Landtman 1933, p. 55; Lawrence and Varjola 2010, pp. 168-169. 
sight distance is also short; for example, in place where an ambush can be successfully organized. In open air areas or on grasslands, which have spread due to agriculture development in Highlands, the stone clubs lost their advantage in comparison with bows, arrows, spears, and shields. Warriors were keeping within the spear distance, so the importance of the shields has increased, and those were also manufactured by Asmat, Kamoro, and Anga. Instead of shield, the rattan armor was produced by Dani, who also stayed spear-distance from their enemies as The Dead Birds (1963) movie by Heider shows [Fig. 9]. Marind-Anim had guerilla-like way of warfare, they did not use shields but rattan wristband, manufactured to protect their arms from a wrist to an elbow and to enable them to parry the attack, occurring with short-distance weapon. A question arises, if the stone club manufacturing went together with head-hunting and cannibalism; the stone clubs were crafted in five areas in total in written-history era, in four of which the cannibalism existed. In three of those the head-hunting was performed. There is one cardinal exception to consider though: in Kamoro area, neither cannibalism, nor head-hunting has occurred. Connection between stone clubs and cannibalism is not therefore strong; but it has its implications for the close connection between head-hunting a stone-club tradition. Warfare stone clubs have become wanted objects for collectors, and we can find many of them in museums and private collections worldwide. This fact makes the clubs' origin determination rather difficult, along with the description of their specific cultural purposes in various societies. As the Asmat, Marind-Asmat, and Kiwai example show, the stone clubs carried a lot of other cultural meaning.

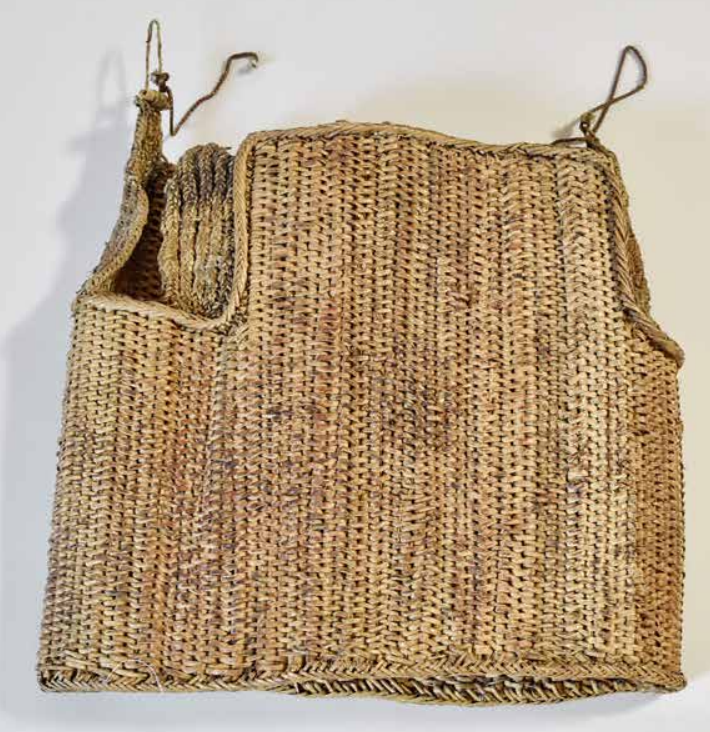

Fig. 9. An example of Dani rattan armor. A private collection

(Photo: Martin Soukup). 


\section{Literature:}

Blackwood, B. (1978). The Kukukuku of the Upper Watut. Oxford: Pitt Rivers Museum.

Chappell, J. and Strathern, M. (1966). Stone Axe Factories in the Highlands of East New Guinea. Proceedings of the Prehistoric Society, 32(5), pp. 96-121.

Connolly, B. and Anderson, R. (1988). First Contact. Harmondsworth: Penguin Books.

Fischer, H. (1986). Sound-Producing Instruments in Oceania. Port Moresby: Institute of Papua New.

Grottanelli, V. (1951). On the 'Mysterious' Baratu Clubs from Central New Guinea. Man, 51, pp. 105-107.

Haddon, A. C. (1895). Evolution in Art. London: Walter Scott.

Haddon, A. C. (1900). A Classification of the Stone Clubs of British New Guinea. The Journal of the Anthropological Institute of Great Britain and Ireland, 30, pp. 221-250.

Hampton, O. W. (1999). Culture of Stone. Texas: A \& M University Press.

Heider, K. (1970). Dugum Dani. New York: Wenner-Gren Foundation for Anthropological Research.

Hughes, I. (1977). New Guinea Stone Age Trade. Canberra: The Australian National University.

Knauft, B. (1993). South Coast New Guinea Cultures. Cambridge: Cambridge University Press.

Kooijman, S. (1952). The Function and Significance of Some Ceremonial Clubs of the Marind Anim, Dutch New Guinea. Man, 52, pp. 97-99.

Kooijman, S. (1984). Art, Art Objects, And Ritual in the Mimika Culture. Leiden: E. J. Brill.

Landtman, G. (1933). Ethnological Collection from the Kiwai District of British New Guinea. Helsingfors: Commission of the Antell Collection.

Lawrence, D. and Varjola, P. (2010). Gunnar Landtman in Papua. Canberra: The Australian National University.

Lemonnier, P. (2004). The Hunt for Authenticity: Stone Age Stories out of Context. The Journal of Pacific History, 39(1), pp. 79-98.

Lewis, A. and Welsch, R. (1998). An American Anthropologist in Melanesia. Vol. 1. Honolulu: University of Hawai'i Press.

MacKenzie, M. (1991). Androgynous Objects. London: Routledge

Maiden, P. (2003). Missionaries, Headhunters \& Colonial Officers. Rockhampton: Central Queensland University Press.

Moore, C. (2003). New Guinea. Honolulu: University of Hawai'i Press.

Moore, D. (1989). Arts and Crafts of Torres Strait. Aylesbury: Shire Ethnography.

Parkinson, R. (2010). Thirty Years in the South Seas. Sydney: Sydney University Press. 
Pospisil, L. (1963). Kapauku Papuan Economy. New Haven: Department of Anthropology, Yale University.

Pretty, G. (1964). Stone Objects Excavated in New Guinea. Royal Anthropological Institute of Great Britain and Ireland, 64, p. 117.

Schmidt, D. (1993). Asmat Art. Leiden: Rijksmuseum voor Volkenkunde.

Schmidt, D. (2003). Kamoro Art. Leiden: Rijksmuseum voor Volkenkunde.

Sillitoe, P. (2017). Made in Niugini. Wantage: Sean Kingston Publishing.

Souter, G. (1967). New Guinea. Sydney: Angus and Robertson.

Summerhayes, G., Leavesley, M., Fairbairn, A., Mandui, H., Field, J., Ford, A. and Fullagar, R. (2010). Human Adaptation and Plant Use in Highland New Guinea 49,000 to 44,000 Years Ago. Science, 330(6000), pp. 78-81.

Swadling, P. (1996). Plumes from Paradise. Port Moresby: Papua New Guinea National Museum.

Waterhouse, M. (2007). Not a Poor Man's Land. Braddon: Halstead Press.

Williams, E. F. (1941). Natives of Lake Kutubu, Papua. Oceania, 11(2), pp. 121-157.

Williams, F. (1936). Papuans of Trans Fly. Oxford: The Clarendon Press.

Young, M. and Clark, J. (2001). An Anthropologist in Papua. Honolulu: Univesity of Hawai'i Press.

Zegwaard, G. (1959). Headhunting Practices of the Asmat of Netherlands New Guinea. American Anthropologist, 61(6), pp. 1020-1041. 